\title{
Pirfenidone reduces profibrotic responses in human dermal myofibroblasts, in vitro
}

\author{
Caroline L. Hall ${ }^{1}$ Adrienne R. Wells ${ }^{1} \cdot$ Kai P. Leung ${ }^{1}$
}

Received: 8 September 2017 / Revised: 15 November 2017 / Accepted: 10 December 2017 / Published online: 1 March 2018

(c) United States \& Canadian Academy of Pathology 2018

\begin{abstract}
Pirfenidone (PFD) is a synthetic small molecule inhibitor with demonstrated anti-inflammatory and antifibrotic properties in vitro and in vivo. The exact mechanism(s) of PFD action remain unclear, due in part to the broad effects of this drug on the complex processes involved in inflammation and fibrosis. While PFD is FDA-approved for the treatment of idiopathic pulmonary fibrosis, the efficacy of this compound for the treatment of dermal fibrosis has not yet been fully characterized. Dermal fibrosis is the pathological formation of excess fibrous connective tissue of the skin, usually the result of traumatic cutaneous injury. Fibroproliferative scarring, caused by delayed wound healing and prolonged inflammation, remains a major clinical concern with considerable morbidity. Despite efforts to identify a therapeutic that targets the fibrotic pathways involved in wound healing to mitigate scar formation, no satisfactory dermal antifibrotic has yet been identified. We aim to better elucidate the antifibrotic mechanism(s) of PFD activity using an in vitro model of dermal fibrosis. Briefly, cultured human dermal fibroblasts were stimulated with TGF- $\beta 1$ to induce differentiation into profibrotic myofibroblast cells. A dose-dependent reduction in cellular proliferation and migration was observed in TGF- $\beta 1$-stimulated cells when treated with PFD. We observed a clear inhibition in the development of essential myofibroblast mechanoregulatory machinery, including contractile F-actin stress fibers containing $\alpha$-SMA and large super-mature focal adhesions. PFD treatment significantly reduced protein levels of major ECM components type I and type III collagen. PFD targeted the p38 MAPK signaling pathway and mitigated profibrotic gene expression profiles. This in vitro data promotes PFD as a potential therapeutic agent for the treatment of dermal fibrosis.
\end{abstract}

\section{Introduction}

Fibroproliferative disorders of the skin, such as hypertrophic scarring (HTS), are characterized by dysregulated collagen production and result in raised, thick, and inflexible scars [1-3]. HTS occurs most commonly after burn injury, surgery, or excessive inflammation and can

Caroline L. Hall and Adrienne R. Wells contributed equally to this work.

Electronic supplementary material The online version of this article (https://doi.org/10.1038/s41374-017-0014-3) contains supplementary material, which is available to authorized users.

Kai P. Leung

kai.p.leung.civ@mail.mil

1 Dental and Craniofacial Trauma and Tissue Regeneration Directorate, United States Army Institute of Surgical Research, 3698 Chambers Pass, Building 3610, Joint Base San Antonio/Fort Sam Houston, TX 78234, USA dramatically diminish patient quality of life [1, 3-5]. HTS contractures and rigidity can limit range of motion and impair day-to-day activities. Available anti-scarring therapies such as surgical management, vascular laser treatment, and pressure therapy, have limited efficacy on the final scar outcome [6, 7].

To identify antifibrotic therapeutics, research has focused on targeting myofibroblasts, the cellular mediators of fibrosis. In the wound bed, transforming growth factor-beta 1 (TGF- $\beta 1$ ) is present at elevated levels and drives a shift in the phenotype of fibroblasts to hyper extracellular matrix (ECM)-producing myofibroblasts [1, 8-12]. Myofibroblasts also express the $\alpha$-smooth muscle isoform of actin ( $\alpha$-SMA) that associates with F-actin stress fibers and augments cell contractile properties [13, 14]. Enlarged focal adhesion complexes in myofibroblasts anchor the contractile stress fibers to the surrounding ECM and mediate the matrix contraction that increases mechanical tension in woundadjacent tissue [15].

Myofibroblasts also mediate fibrosis through collagen production. Collagen type I and collagen type III are the 
major collagen isoforms present in the skin, comprising $80-85 \%$ and $10-15 \%$ of the total collagen content, respectively [16]. Overall collagen I and III production is increased significantly in fibrotic disorders of the skin, such as scarring and keloid progression [17-19]. Although the quantity of collagen I is consistently greater than collagen III throughout the remodeling phase of wound healing, collagen III production initially increases relative to collagen I $[17,18,20]$. The ratio of collagen I/collagen III shifts over time with scar maturation. Excessive collagen production and decreased collagen I/III ratio contributes to abnormal crosslinking and disorganized fiber bundle orientation associated with fibrotic scarring [17-20].

TGF- $\beta 1$ exerts its profibrotic effects on fibroblasts through both canonical SMAD-mediated and non-canonical SMAD-independent signaling pathways [21]. Consequently, many antifibrotic therapies target TGF- $\beta$ signaling and modulate profibrotic mediators. One promising candidate is the small molecule inhibitor pirfenidone (PFD). Pirfenidone (5-methyl-1-phenyl-2-(1H)-pyridone) is FDAapproved for the treatment of idiopathic pulmonary fibrosis and exerts anti-inflammatory and antifibrotic effects in a variety of in vitro and in vivo models of fibrotic disease [22]. While the exact mechanism(s) of PFD remain unknown, previous studies demonstrated its effectiveness at mitigating myofibroblast differentiation, proliferation, and profibrotic cytokine production in both in vitro and in vivo models of lung, liver, and renal fibrosis [22, 23]. The potential of PFD as a topical therapeutic agent for use during wound healing [24, 25] or following HTS development [26] has been suggested, however the mechanism by which PFD exerts its antifibrotic properties on dermal cells has not been fully described [24-28].

In this paper, we investigated the effects of PFD on TGF$\beta 1$-stimulated dermal fibroblasts. PFD treatment significantly reduced cellular proliferation, migration, and myofibroblast differentiation. Specifically, PFD reduced the development of F-actin stress fibers, super-mature focal adhesions, de novo $\alpha$-SMA expression, and collagen production. PFD targeted TGF- $\beta 1$ signaling, reducing p38 MAPK activation and regulating transcription of fibrosisassociated genes.

\section{Materials and methods}

\section{Cell culture and treatments}

Adult normal human dermal fibroblast cells (NHDF) were isolated from the breast skin of a female 41-year-old by PromoCell (Heidelberg, Germany). NHDF were cultured in fibroblast growth media-2 (FGM2; Lonza, Rockland, ME, USA) supplemented with $1 \%$ penicillin-streptomycin
(Gibco Life Technologies, Carlsbad, CA, USA) and maintained at $37{ }^{\circ} \mathrm{C}$ with $5 \% \mathrm{CO}_{2}$. All experiments were performed using cells cultured within ten passages. Cell cycles were synchronized for $24 \mathrm{~h}$ in serum-free media (SFM) supplemented with $1 \%$ penicillin-streptomycin prior to stimulation with TGF- $\beta 1$ (R\&D Systems, Minneapolis, MN, USA) in the presence or absence of PFD (Tocris Bioscience, Avonmouth, United Kingdom). Cells were stimulated with $10 \mathrm{ng} / \mathrm{mL}$ TGF- $\beta 1$ alone or in the presence of PFD (0.0-3.0 mg/mL). A fresh PFD solution was prepared prior to each experiment where PFD was dissolved in SFM at $3 \mathrm{mg} / \mathrm{mL}$, mixed by vortex, and warmed to $37^{\circ} \mathrm{C}$ prior to use. Untreated serum-starved cells were grown in SFM and assayed at the same time to serve as controls.

\section{Cytotoxicity assay}

NHDF cells were seeded at a density of $10^{4}$ cells/well in Falcon 96-well tissue culture microplates (Corning Incorporated-Life Sciences, Durham, NC, USA). In order to establish a non-toxic PFD dosage, quiescent cells were stimulated in triplicate with TGF- $\beta 1$ alone or in the presence of PFD (0.0-3.0 mg/mL) for $48 \mathrm{~h}$. Cells were pulsed with $100 \mu \mathrm{L}$ Caspase-Glo 3/7 reagent (Promega, Madison, WI, USA) and incubated at $37^{\circ} \mathrm{C}$ for $30 \mathrm{~min}$. Luminescence was measured using the BioTek Synergy H1 microplate reader (BioTek, Winooski, VT, USA) as an indicator of apoptosis.

\section{Cell proliferation assay}

Cell growth was measured using the WST-1 cell proliferation assay kit (Cayman Chemical, Ann Arbor, MI, USA). Briefly, cells were seeded as in the cytotoxicity assay in $100 \mu \mathrm{L}$ per well of 96-well tissue culture microplates (Corning Incorporated-Life Sciences). Quiescent cells were treated with PFD $(0.0-1.0 \mathrm{mg} / \mathrm{mL})$ either $24 \mathrm{~h}$ prior to, concurrent with, or $24 \mathrm{~h}$ following TGF- $\beta 1$ stimulation. NHDF were pulsed with $10 \mu \mathrm{L} /$ well WST-1 reagent and incubated at $37^{\circ} \mathrm{C}$ for two hours. Absorbance at $450 \mathrm{~nm}$ was measured over the course of four days as an indicator of proliferation.

\section{Cell attachment and migration assay via electric cell-substrate impedance sensing (ECIS)}

Cell attachment and migration behavior was assayed in 96W1E + microplates via the ECIS-Z system (Applied Biophysics, Troy, NY, USA). Cells covering the $350 \mu \mathrm{m}$ diameter gold-plated electrodes cause impedance to a small $1 \mu \mathrm{A}$ alternating current. This impedance is measured as output at $24 \mathrm{kHz}$ and is proportional to electrode coverage. Prior to cell seeding, the electrodes were cleaned with 10 mM L-cysteine (Sigma, St. Louis, MO, USA) and coated 
Table 1 List of antibodies used in this study

\begin{tabular}{|c|c|c|c|c|c|c|}
\hline Antibody & Species & Clone & $\#$ & Manufacturer & Dilution & Application \\
\hline$\alpha$-SMA & Mouse & $1 \mathrm{~A} 4$ & 7817 & Abcam & $1: 20 / 1: 100$ & $\mathrm{WB} / \mathrm{ICC}$ \\
\hline Collagen Type I & Rabbit & - & 34710 & Abcam & $1: 1000 / 1: 500$ & WB/ICC \\
\hline Collagen Type III & Rabbit & - & 7778 & Abcam & $1: 500 / 1: 500$ & WB/ICC \\
\hline Phospho-SMAD2/SMAD3 & Rabbit & $\mathrm{D} 27 \mathrm{~F} 4$ & 8828 & Cell Signaling Technologies & $1: 50$ & WB \\
\hline Phospho-p38 MAPK & Rabbit & $3 \mathrm{D} 7$ & 9215 & Cell Signaling Technologies & $1: 50$ & WB \\
\hline SMAD2/3 & Rabbit & D7G7 & 8685 & Cell Signaling Technologies & $1: 1000$ & WB \\
\hline p38 MAPK & Rabbit & D13E1 & 8690 & Cell Signaling Technologies & $1: 1000$ & WB \\
\hline TATA binding protein & Mouse & mAbcam 51841 & 51841 & Abcam & $1: 100$ & WB \\
\hline GAPDH & Mouse & $6 \mathrm{C} 5$ & 374 & Millipore & $1: 500$ & WB \\
\hline Vinculin & Mouse & hVin-1 & V9264 & Sigma & $1: 300$ & ICC \\
\hline
\end{tabular}

$\alpha$-SMA alpha-smooth muscle actin, MAPK mitogen-activated protein kinase, GAPDH glyceraldehyde 3-phosphate dehydrogenase, WB Western blot, ICC immunocytochemistry

with rat-tail collagen I $(200 \mu \mathrm{g} / \mathrm{mL}$ in $0.15 \mathrm{M} \mathrm{NaCl}, \mathrm{BD}$ Biosciences, San Jose, CA, USA). A media-alone baseline impedance was recorded for each well. To achieve a confluent monolayer of cells, NHDF were seeded at a density of $1.6 \times 10^{4}$ cells/well. ECIS measurements confirmed cell attachment and after 3-4 h, media was replaced with SFM. After $18 \mathrm{~h}$ in SFM, select wells received a $20 \mathrm{~s}$ pulse at $2500 \mu \mathrm{A}$, killing cells in contact with the electrode and creating a 2D "wound." After wounding, half of the media was replaced with a $2 \times$ solution of treatment (TGF- $\beta 1$ alone or in the presence of PFD at $0.1,0.5$, or $1.0 \mathrm{mg} / \mathrm{mL}$ ) administered in quadruplicate wells. Impedance was recorded over the course of four days and analyzed using Excel (Microsoft Office 2010). To create a normalized impedance measurement where " 0 " represents the impedance of mediaalone (no live cells on the electrode) and " 1 " represents a confluent monolayer of cells, first the baseline impedance measured before seeding cells was subtracted from all impedance measurements. Next, the pre-wound impedance level was determined for each well by averaging the last hour of impedance measurements before the wound. Baseline-subtracted impedance was divided by this prewound impedance and the resulting normalized impedance was used for all subsequent analysis. The maximum normalized recovery and the time to reach 0.5 normalized recovery was determined for each well.

\section{Immunocytochemistry and confocal imaging}

Unless otherwise specified, all immunocytochemistry reagents were acquired from ThermoFisher Scientific. NHDF were seeded at a density of $2 \times 10^{3}$ cells/well into eight-well Nunc Lab-Tek chambered slides. Cells were treated with TGF- $\beta 1$ alone or in the presence of PFD $(0.1$, 0.5 , or $1.0 \mathrm{mg} / \mathrm{mL}$ ) and fixed before treatment $\left(t_{0}\right)$ or one to four days after treatment. Cells were fixed for $20 \mathrm{~min}$ in $4 \%$ paraformaldehyde then stored at $4{ }^{\circ} \mathrm{C}$ in phosphate-buffered saline (PBS) until staining. Prior to permeabilization, cell membranes were stained with Alexa Fluor 488-tagged wheat germ agglutinin (WGA, 1:200). Cells were permeabilized for $10 \mathrm{~min}$ in $0.1 \%$ Triton X-100 (Sigma) and blocked for $1 \mathrm{~h}$ with $5 \%$ normal goat serum in $0.1 \%$ Tween 20 (Sigma) in PBS. Slides were incubated with primary antibody for $\alpha$-SMA, collagen I, collagen III, or vinculin in blocking solution for $1 \mathrm{~h}$ at room temperature (see Table 1 for manufacturer, dilution). Secondary antibody (Alexa Fluor 568-tagged IgG $(\mathrm{H}+\mathrm{L})$ goat anti-mouse or goat antirabbit, 1:1000), F-actin label (Alexa Fluor 647 phalloidin, 1:40), and DNA label (Hoechst 33342, 1:2000) were diluted in blocking solution and incubated on slides for $1 \mathrm{~h}$ at room temperature. Confocal images were acquired with the same laser power, gain, and digital offset for all slides from an individual experiment. Multiple $z$-planes were acquired with either a Plan-Apochromat $10 \times, 0.45$ NA (F-actin, $\alpha$-SMA, collagen, $z$-distance $3.13 \mu \mathrm{m}$ ) or an LD C-Apochromat $40 \times$, 1.1 NA (vinculin, $z$-distance $0.5 \mu \mathrm{m}$ ) objective on a Zeiss 710 confocal microscope (Zeiss, Thornwood, NY, USA). Maximum projection images created in ImageJ (National Institutes of Health, Bethesda, MD, USA) combined data from multiple z-planes and were used for figure creation and subsequent analysis.

\section{Image analysis}

To quantify $\alpha$-SMA, F-actin, and collagen from confocal images, analysis routines were optimized for each labeled protein. In images of $\alpha$-SMA labeled cells, many cells did not express $\alpha$-SMA and had no above-background signal to capture. Thus, an additional membrane stain (WGA) was used to define the cell boundaries. A cell was determined $\alpha-\mathrm{SMA}^{+}$by the mean $\alpha$-SMA intensity within its cell boundaries, using cell measurements from visibly negative 
$t_{0}$ SFM control cells as a cut-off. CellProfiler [29] software was used to define cell boundaries and measure the mean cell intensity of $\alpha$-SMA (Broad Institute, Boston, MA, USA). Briefly, nuclei were identified via an automated threshold of the nuclear Hoechst image and the corresponding whole cell WGA stain image was segmented into individual cells. A watershed algorithm-based segmentation routine used nuclear regions as seeds, expanding them to encompass the entire cell. The sharp intensity gradient found at the cell edge determined where to end the cell boundary. Any errors in segmentation were corrected manually within the CellProfiler pipeline.

To quantify changes to F-actin accumulation with different treatments, phalloidin staining was included in the immunocytochemistry assays of $\alpha$-SMA, collagen I, and collagen III. Phalloidin imaging data was compiled from seven independent experiments. In contrast to $\alpha$-SMA, all NHDF cells imaged contained some level of measurable phalloidin signal. Thus, the mean intensity of fluorescent phalloidin per WGA cell region was used to compare relative F-actin abundance. Due to phalloidin signal variation between experiments, we normalized the mean cell intensity per image for each treatment/time to the mean cell intensity per image for time-matched control SFM samples. The SFM samples showed low levels of phalloidin staining in samples from all time points measured.

In images of NHDF labeled for collagen I or III, only intracellular collagen was detectible and was localized to the endoplasmic reticulum (ER)/Golgi compartment. This compartment varied in relative size and shape in each cell. Thus, a measure of collagen intensity using the whole cell as a region of interest would bias measurements for small cells with proportionally larger ER/Golgi compartments over larger cells with relatively smaller ER/Golgi compartments. To more accurately describe the relative level of intracellular collagen, an area of collagen protein localization was defined in each cell and used as the region of interest for mean collagen intensity per cell. Based on established image analysis techniques [30], a custom ImageJ macro was used to define these regions. The region of collagen localization in each cell was revealed by smoothing and background subtracting the original images. First, images were smoothed with a Gaussian $(\sigma=1)$ then median (radius $=2$ ) filter. To generate a smoothedbackground image the filtered image was additionally smoothed with a median filter (radius $=100$ ). After subtracting the smoothed background from the smoothed image a threshold was applied that created a binary image containing individual regions of above-background collagen signal for each cell. The immunolabeled collagen fluorescent intensity from the original image was then measured in these regions. To observe changes in intracellular collagen levels over time and compare data across experiments, the mean cell intensity per image was calculated for each treatment/time and was normalized to the mean cell intensity per image for SFM samples fixed before treatment $\left(t_{0}\right)$.

\section{Western blot analysis}

NHDF cells were seeded at a density of $4.5 \times 10^{5}$ cells in Falcon $100 \mathrm{~mm}$ cell culture dishes (Corning IncorporatedLife Sciences) and grown to $70 \%$ confluence before $24 \mathrm{~h}$ serum starvation and subsequent treatment. Undiluted cell culture media was collected for quantification of soluble secreted collagen. NHDF were directly lysed on the culture plate in $400 \mu \mathrm{L}$ Pierce RIPA buffer (ThermoScientific, Rockford, IL, USA) supplemented with Pierce protease inhibitors, EDTA-free (ThermoScientific). Plates were then scraped to collect a fraction containing whole cell lysate and adherent collagen. Samples were clarified by centrifugation at $14,000 \mathrm{rpm}$ for $15 \mathrm{~min}$ at $4{ }^{\circ} \mathrm{C}$. Protein concentration was quantified in culture media and lysates using the BCA assay (ThermoScientific). Immune detection of proteins extracted from cultured cells was performed using the Simple Wes capillary-based Western blot technology as described previously (Protein Simple, San Jose, CA, USA) [31-34]. Briefly, samples were adjusted to equivalent protein concentration using sample buffer (Protein Simple), four parts protein sample was combined with one part master mix (Protein Simple) containing fluorescent molecular weight markers and DTT $(40 \mathrm{mM})$. Samples were heated at $95^{\circ} \mathrm{C}$ for $8 \mathrm{~min}$ for detection of collagen or $5 \mathrm{~min}$ for detection of all other protein targets. Protein samples, primary antibodies (Table 1), biotinylated ladder and its corresponding secondary streptavidin-HRP conjugate, blocking reagent, HRPconjugated secondary antibody, chemiluminescent substrate, and wash buffer (Protein Simple) were dispensed into prefilled microplates containing separation and stacking matrices. The assay plate was then loaded into the Wes instrument (Protein Simple) where the separation by electrophoresis and immunoblotting steps were performed using the automated capillary system. Protein quantification was performed using the Compass software for Simple Western (v3.0.9; Protein Simple).

\section{Kinase signaling pathway array}

NHDF cells were seeded at a density of $4.5 \times 10^{5}$ cells in Falcon $100 \mathrm{~mm}$ cell culture dishes (Corning Incorporated) as described for Western blot analysis. Antibody-based kinase signaling arrays were performed according to the manufacturer's instructions for the PathScan Stress and Apoptosis Signaling Antibody Array Kit (Cell Signaling Technology, Danvers, MA, USA) and the Proteome Profiler Human Phospho-MAPK Array Kit (R\&D Systems, Inc., 

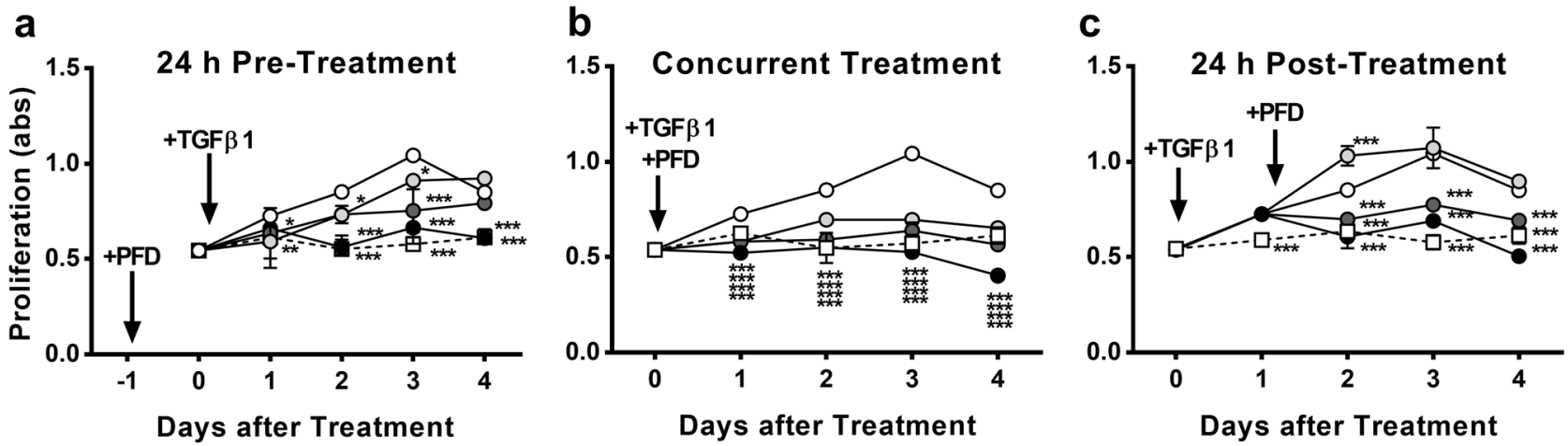

\begin{tabular}{llllllllll}
\hline$-\square-\cdot S F M$ & - & 0.0 & 0 & $0.1 \mathrm{P}$ & - & $0.5 \mathrm{P}$ & $\rightarrow$ & 0 & $1.0 \mathrm{mg} / \mathrm{mL}$ PFD \\
\hline
\end{tabular}

Fig. 1 PFD inhibited TGF- $\beta 1$-induced cell proliferation in human NHDF cells. Proliferation assay of NHDF cells stimulated with TGF- $\beta 1$ alone or in the presence of PFD. Cell growth was determined by WST-1 absorbance at $450 \mathrm{~nm}$. Proliferation was measured for each time point over the course of four days. Cells were treated with
PFD (a) $24 \mathrm{~h}$ prior to TGF- $\beta 1$, (b) concurrent to TGF- $\beta 1$, or (c) $24 \mathrm{~h}$ post-TGF- $\beta 1$ stimulation. Data represents average absorbance value \pm standard deviations (s.d.) from one representative experiment of three. $* P<0.05, * * P<0.01, * * * P<0.001$ compared with TGF- $\beta 1$ only (no PFD)
Minneapolis, MN, USA). Briefly, cell lysates were prepared in lysis buffer supplemented with Pierce protease and phosphatase inhibitor mini tablets, EDTA-free (ThermoScientific). Phosphorylation events were determined by chemiluminescent reaction and quantified by densitometry using Image Lab software (v5.2.1; Bio-Rad Laboratories, Inc., Hercules, CA, USA). Detection of phosphorylated levels of p38 MAPK and SMAD2/3 was validated and quantified by Western blot as described above. Control cells were pre-treated with either the p38 inhibitor, (5Z)-7-oxozeaenol, or the T $\beta$ RI/SMAD2 inhibitor, SB-505124, (Tocris, $10 \mu \mathrm{M}$ ).

\section{Gene expression analysis}

NHDF were seeded at a density of $4.65 \times 10^{5}$ cells in 100 $\mathrm{mm}$ cell culture dishes (Corning Incorporated) and grown for $24 \mathrm{~h}$ in FGM2 before serum starvation for $24 \mathrm{~h}$ in SFM. Cells were treated with TGF- $\beta 1$ alone or in the presence of PFD $(0.1$ or $0.5 \mathrm{mg} / \mathrm{mL})$ for $12,24,48$ or $72 \mathrm{~h}$ before collecting cell pellets. Cells were gently removed from culture plates with $0.025 \%$ Trypsin/0.01\% EDTA (TE, Gibco) and Defined Trypsin Inhibitor (DTI, Gibco), split into two aliquots, centrifuged at $500 \times g$ for $5 \mathrm{~min}$ at $4{ }^{\circ} \mathrm{C}$, and snap frozen in liquid nitrogen. Cell pellets were stored at $-80^{\circ} \mathrm{C}$ until total RNA was isolated from one aliquot of pelleted cells, cDNA was synthesized, and quantitative real-time PCR (qRT-PCR) with $2.5 \mathrm{ng}$ of cDNA per sample was run on Human Fibrosis $\mathrm{RT}^{2}$ Profiler PCR Arrays (Qiagen Genomic Service Core, Frederick, MD, USA). Results were normalized to the least variable housekeeping gene, RPLPO, and analyzed with Excel using the $2^{-\Delta \Delta C T}$ method [35].
To validate the array results, RNA was isolated from reserved aliquots of cells from above experiments. An RNeasy Plus Mini Kit (Qiagen, Valencia, CA, USA) was used according to the manufacturer's protocol. A NanoDrop 2000 spectrophotometer (ThermoFisher Scientific) was used to measure RNA quality and quantity, and a 4200 TapeStation (Agilent Technologies, Santa Clara, CA, USA) was used to verify RNA integrity. An $\mathrm{RT}^{2}$ First Strand Kit (Qiagen) was used to synthesize cDNA, and the expression levels of select genes were detected by using the iQ SYBR Green Supermix (BioRad, Hercules, CA, USA) according to the manufacturer's instructions on a StepOnePlus Real-Time PCR system (Applied Biosystems, Foster City, CA, USA). All data were normalized to RPLPO and analyzed using the $2^{-\Delta \Delta C T}$. Primers used are listed in Table 2 .

\section{Statistical analysis}

For all time course experiments, time is given relative to TGF$\beta 1$ treatment, denoted $t_{0}$ or time " 0 ". Data was graphed and analyzed for statistical significance using the GraphPad Prism v5.00 for Windows (GraphPad Software, San Diego, CA, USA). Statistical significance for cytotoxicity, proliferation, kinase phosphorylation, Western blot, and immunocytochemistry analysis was determined by two-way ANOVA with repeated measures using the Bonferroni post-test, where statistical significance was indicated by $P<0.05$. The oneway ANOVA with Bonferroni post-test was used for all ECIS experiments and validation $\mathrm{qRT}-\mathrm{PCR}$ data comparing $\Delta \mathrm{Ct}$ values of TGF- $\beta 1$ alone with TGF- $\beta 1+$ PFD treated samples from two independent experimental runs. 
Table 2 List of primers for qRT-PCR

\begin{tabular}{lll}
\hline Gene & Forward primer $\left(5^{\prime} \rightarrow 3^{\prime}\right)$ & Reverse primer $\left(3^{\prime} \rightarrow 5^{\prime}\right)$ \\
\hline$M M P 1$ & GCTAACAAATACTGGAGGTATGATG & GTCATGTGCTATCATTTTGGGA \\
GREM1 & CGCCACGCGTCGAAA & CACCTTGGGACCCTTTCTTT \\
ITGA3 & GCCTGCCAAGCTAATGAGAC & ACCTGAAGGTCCCTTGTGTG \\
ACTA2 & AGCGTGGCTATTCCTTCGT & CTCATTTTCAAAGTCCAGAGCTACA \\
COL1A2 & TGTGGATACGCGGACTTTGT & CAGCAAAGTTCCCACCGAGA \\
$C O L 3 A 1$ & GGCATTCCTTCGACTTCTCTC & TGTGTTTCGTGCAACCATCC \\
$T G F B 1$ & CAACGAAATCTATGACAAGTTCAAGCAG & CTTCTCGGAGCTCTGATGTG \\
$T G F B 2$ & TGGTGAAAGCAGAGTTCAGAG & CACAACTTTGCTGTCGATGTAG \\
$T G F B 3$ & TACTGCTTCCGCAACTTGGA & GCTTCAGGGTTCAGAGTGTTG \\
$T H B S 1$ & AATGAGAACCTGGTGTGCGT & GCGGTCTCCCACATCATCTC \\
$S E R P I N E 1$ & TGGTTCTGCCCAAGTTCTCCCTG & TGCCACTCTCGTTCACCTCG \\
$R P L P 0$ & CTGGAAGTCCAACTACTTCCT & CATCATGGTGTTCTTGCCCAT \\
$H S P 90 A B 1$ & TCAAGATGCCTGAGGAAGTGC & TTGTCCAAGGCATCAGAAGCA \\
\hline
\end{tabular}

\section{Results}

\section{PFD inhibits TGF- $\beta 1$-induced proliferation}

Cellular proliferation was measured by the colorimetric WST-1 assay in adult NHDF monolayers stimulated with TGF- $\beta 1$ alone or in the presence of PFD (Fig. 1). TGF- $\beta 1$ stimulated a statistically significant increase in cell proliferation by day 1 , an effect that continued to increase over the course of four days (compare open circle traces, TGF- $\beta 1$, to squares with dotted line, SFM control, Fig. 1). When given concurrent to TGF- $\beta 1$, PFD significantly reduced the proliferative response in a dose-dependent manner. The highest dose of PFD, $1.0 \mathrm{mg} / \mathrm{mL}$, decreased cell growth to levels similar to the quiescent SFM control (Fig. 1b). Pre-treatment with PFD $24 \mathrm{~h}$ before TGF$\beta 1$ stimulation also inhibited proliferation, although the inhibitory effects at the lowest dose $(0.1 \mathrm{mg} / \mathrm{mL})$ were slightly lessened. Cells treated with PFD $24 \mathrm{~h}$ after TGF- $\beta 1$ stimulation showed a statistically significant reduction in proliferation at the two highest doses of PFD (0.5 and 1.0 $\mathrm{mg} / \mathrm{mL})$. However, the lowest dose $(0.1 \mathrm{mg} / \mathrm{mL})$ initially increased cell growth at day 2 and appeared to have no effect on TGF- $\beta 1$-stimulated growth at later time points (Fig. 1c).

\section{PFD inhibits myofibroblast differentiation}

Using immunocytochemistry, we detected $\alpha-\mathrm{SMA}^{+}$cells after two days of TGF- $\beta 1$ treatment and the percentage $\alpha$-SMA ${ }^{+}$ cells increased from 30 to greater than $80 \%$ of imaged cells by day 4 (Fig. 2a, b). PFD treatment at $0.5 \mathrm{mg} / \mathrm{mL}$ delayed detectible myofibroblast transformation until day 3 and showed a significantly lower percentage of $\alpha-\mathrm{SMA}^{+}$cells at day 4. The lower $0.1 \mathrm{mg} / \mathrm{mL}$ dose of PFD slightly reduced the TGF- $\beta 1$ effect at days 3 and 4 (Fig. 2a, b).

Western blot analysis of cell lysates confirmed these results. Cultures stimulated with TGF- $\beta 1$ alone (no PFD) showed increased protein levels of $\alpha$-SMA by day 2 and detectible $\alpha$-SMA continued to increase over time (Fig. 2c, d). The lowest PFD dose, $0.1 \mathrm{mg} / \mathrm{mL}$, initially did not reduce $\alpha$-SMA production, instead appearing to stimulate protein production at days 2 and 3 . This low dose displayed a delayed inhibitory response and only reduced $\alpha$-SMA levels at day 5 . The $0.5 \mathrm{mg} / \mathrm{mL}$ PFD dose delayed $\alpha$-SMA protein expression until day 3 and maintained a low level of expression until day 5. Whereas, the highest PFD dose tested, $1.0 \mathrm{mg} / \mathrm{mL}$, completely abolished detectible $\alpha$-SMA protein at all times tested.

\section{PFD reduces collagen production}

Collagen I and III proteins were measured at multiple points of their biosynthesis pathway by immunocytochemistry and Western blot. Immunocytochemistry showed that TGF- $\beta 1$ treatment increased intracellular collagen $\mathrm{I}$ over time (Fig. 3a, b). PFD treatment at $1.0 \mathrm{mg} / \mathrm{mL}$ abolished this effect by day 1 . Surprisingly, neither TGF- $\beta 1$ nor PFD treatment altered intracellular collagen III in this assay (Fig. 3e, f).

Western blot analysis showed TGF- $\beta 1$ treatment significantly increased levels of collagen type I and type III detectible in the lysate/adherent collagen fraction within the first $24 \mathrm{~h}$ and in the soluble medium fraction by day 4 (Fig. 3). Only the $1.0 \mathrm{mg} / \mathrm{mL}$ PFD treatment is depicted in the Western blot results as the two lower doses of PFD $(0.1$ and $0.5 \mathrm{mg} / \mathrm{mL})$ did not significantly affect collagen production (data not shown). In the soluble culture 
a

\section{Days after Treatment}
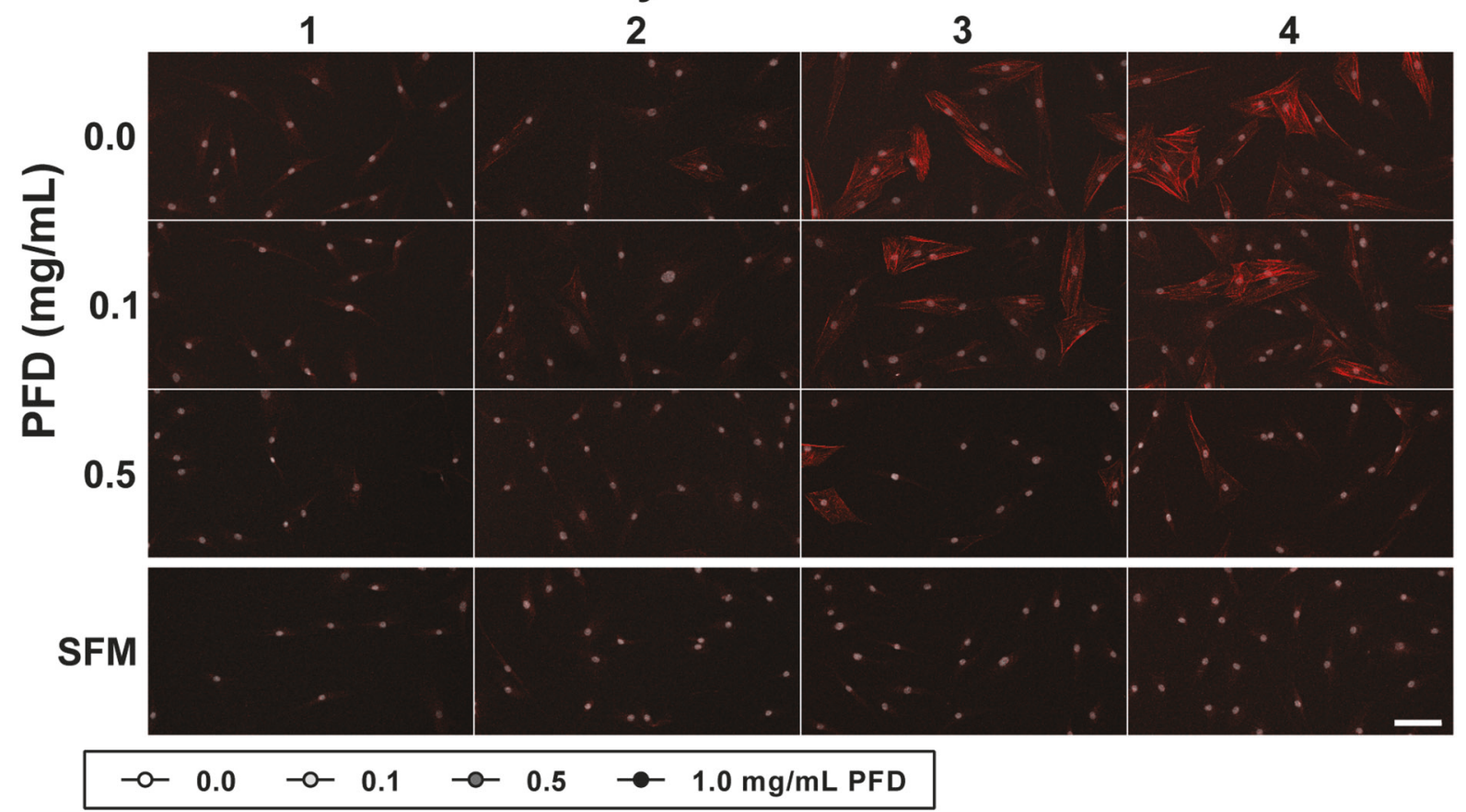

b

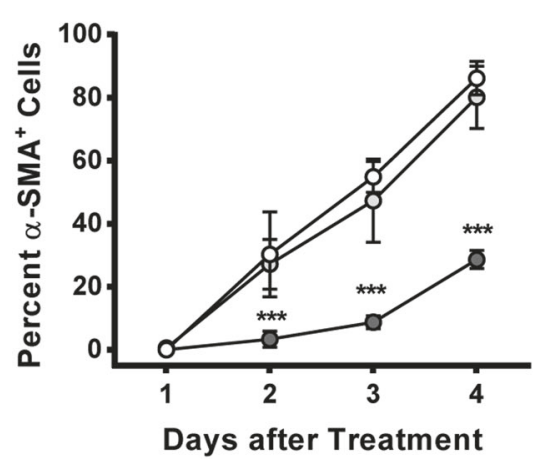

C

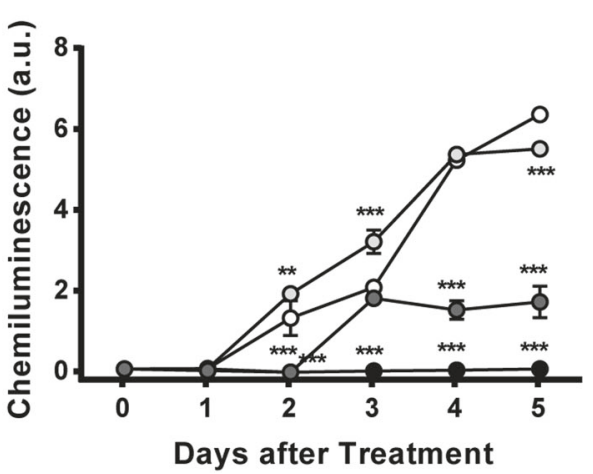

d

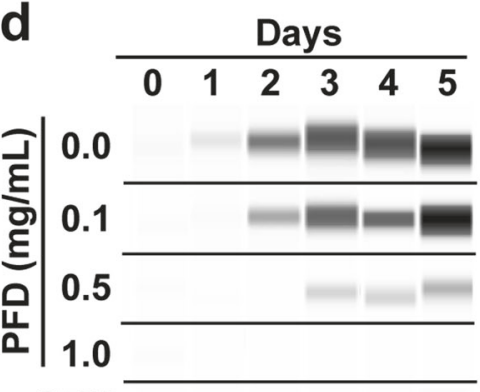

Fig. 2 PFD reduced $\alpha$-SMA protein production in NHDF in a dosedependent manner. Untreated cells in SFM are shown for comparison. a Cells treated with TGF- $\beta 1$ alone or in the presence of PFD were fixed 1-4 days after treatment and stained for $\alpha$-SMA (red) and Hoechst (white). Scale Bar is $100 \mu \mathrm{m}$. b Mean $\alpha$-SMA intensity per cell was measured with CellProfiler to determine the percent $\alpha-\mathrm{SMA}^{+}$cells per treatment group. Average \pm s.d. of percent $\alpha-\mathrm{SMA}^{+}$cells over three images per treatment group shown for the representative dataset. Data is from one representative experiment of two. Protein levels of $\alpha$-SMA were measured in response to TGF- $\beta 1$ and PFD treatment as determined by (c) chemiluminescence quantification shown in arbitrary units (a.u.) of (d) Western blot analysis. Data represents average chemiluminescence \pm s.d. from one representative experiment of three. ${ }^{*} P<0.05$, $* * P<0.01, * * * P<0.001$ compared with TGF- $\beta 1$ only (no PFD) medium fraction, PFD treatment significantly reduced collagen I by day 5 (Fig. 3d). PFD caused a slight reduction of collagen $\mathrm{I}$ in the lysate/adherent collagen fraction but was not statistically significantly (Fig. 3c). Compared to the soluble media and lysate/adherent protein fractions, PFD treatment affected intracellular collagen production earlier and to a greater degree (Fig. 3a, b). Collagen III levels were significantly reduced in the culture medium by day 3 (Fig. 3h) and in the lysate/ adherent fraction by day 1 (Fig. $3 \mathrm{~g}$ ).

\section{PFD reduces F-actin stress fiber and super-mature focal adhesion complex development}

As previously reported [36, 37], TGF- $\beta 1$ stimulation caused an early shift (one day after TGF- $\beta 1$ stimulation) of cytoplasmic globular actin into filamentous actin stress fibers. As very little $\alpha$-SMA was expressed at this time point, the $F$-actin found one day after TGF- $\beta 1$ treatment was likely composed mostly of other actin isoforms (e.g., $\beta$-actin). The relative abundance of F-actin was detected with 

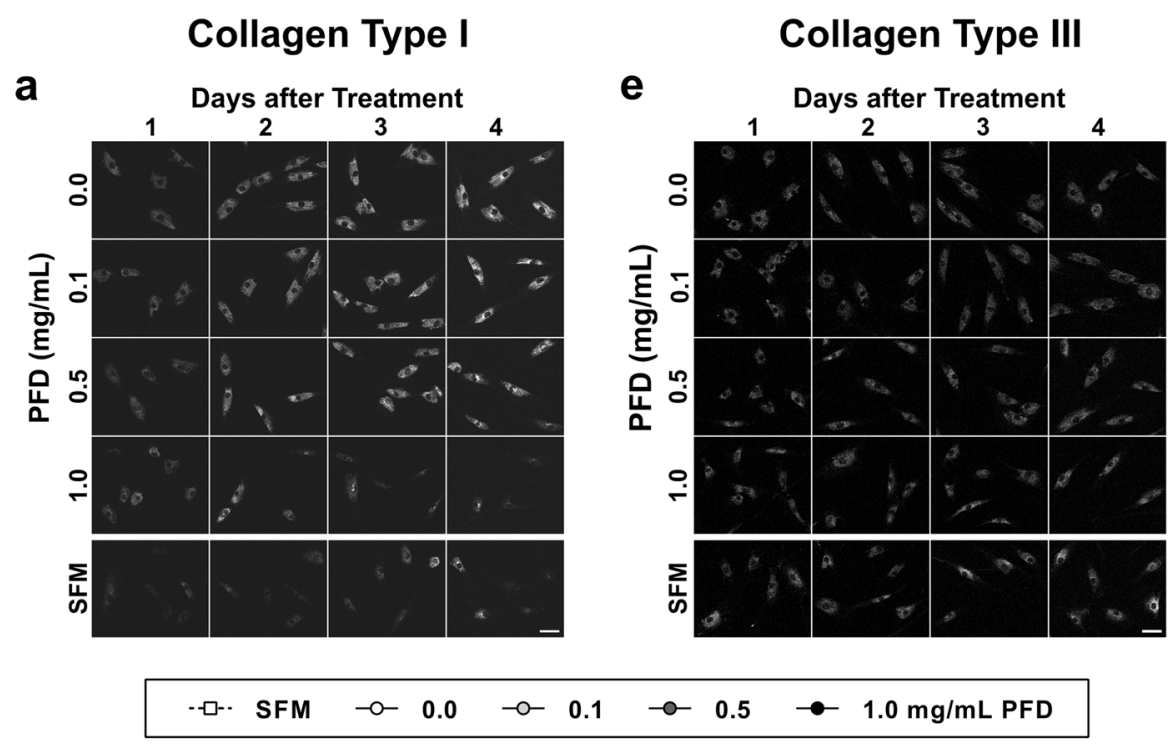

b

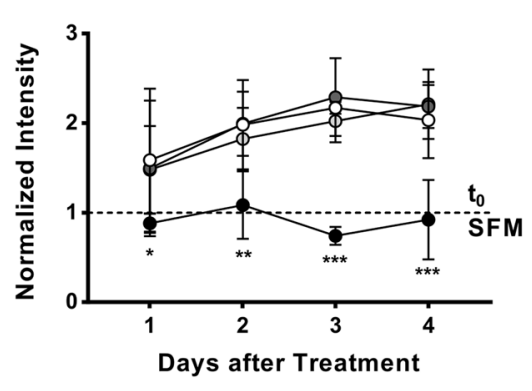

C
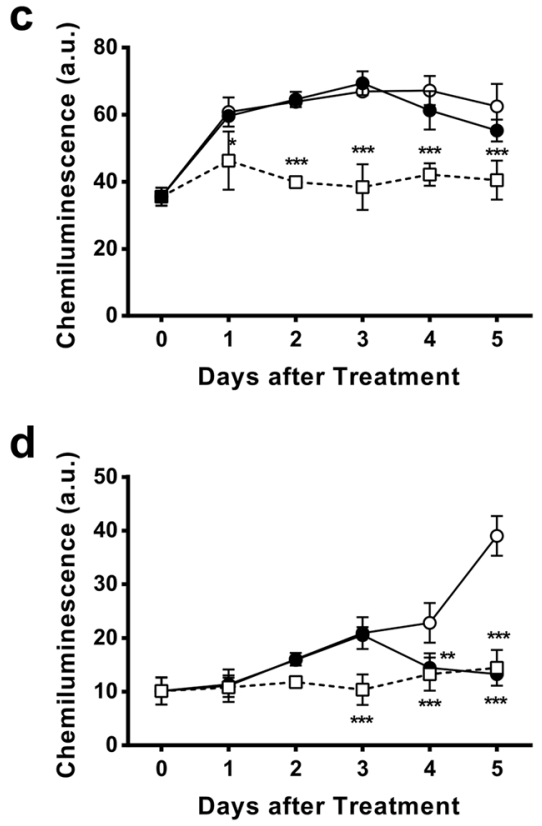

Fig. 3 PFD reduced expression of collagen type I and type III. Untreated cells in SFM are shown for comparison. a, e Cells treated with TGF- $\beta 1$ alone or in the presence of PFD were fixed 1-4 days after treatment and stained for (a) collagen I or (e) collagen III. Scale bar is $50 \mu \mathrm{m}$. b, f Mean collagen intensity per cell was measured for each image with ImageJ and normalized to the mean collagen intensity per cell for images from untreated cells at $t_{0}$. Data represents average \pm s.d. over three experimental runs. Protein production of collagen types I f

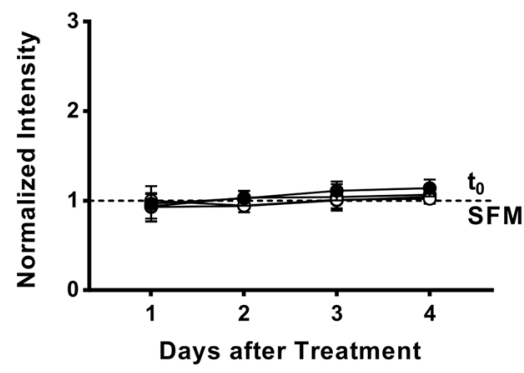

g

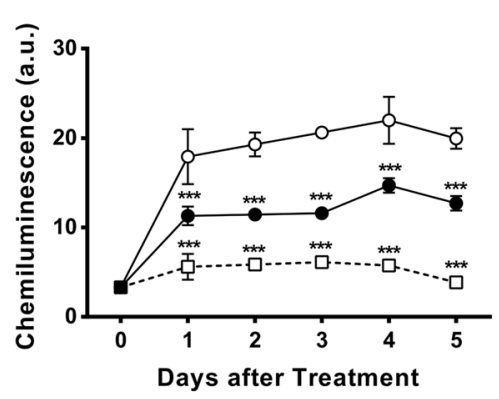

h

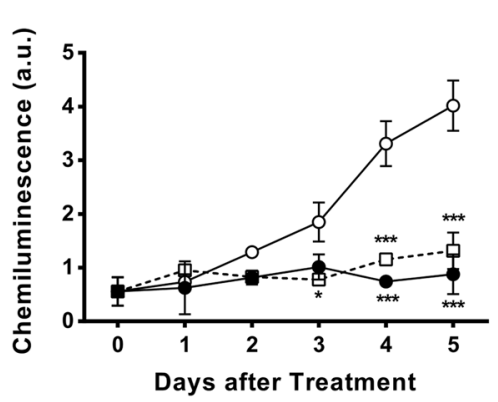

and III were detected by Western blot analysis. The culture medium was removed prior to on-plate cell lysis, after which plates were scraped to collect lysate/adherent collagen fraction. Chemiluminescence was quantified for collagen I and collagen II in (c, g) lysate/ adherent collagen fractions and in (d, h) culture medium fractions, respectively. Data represents average chemiluminescence \pm s.d. from one representative experiment of two. $* P-<0.05, * * P<0.01$, $* * * P<$ 0.001 compared with TGF- $\beta 1$ only (no PFD) 

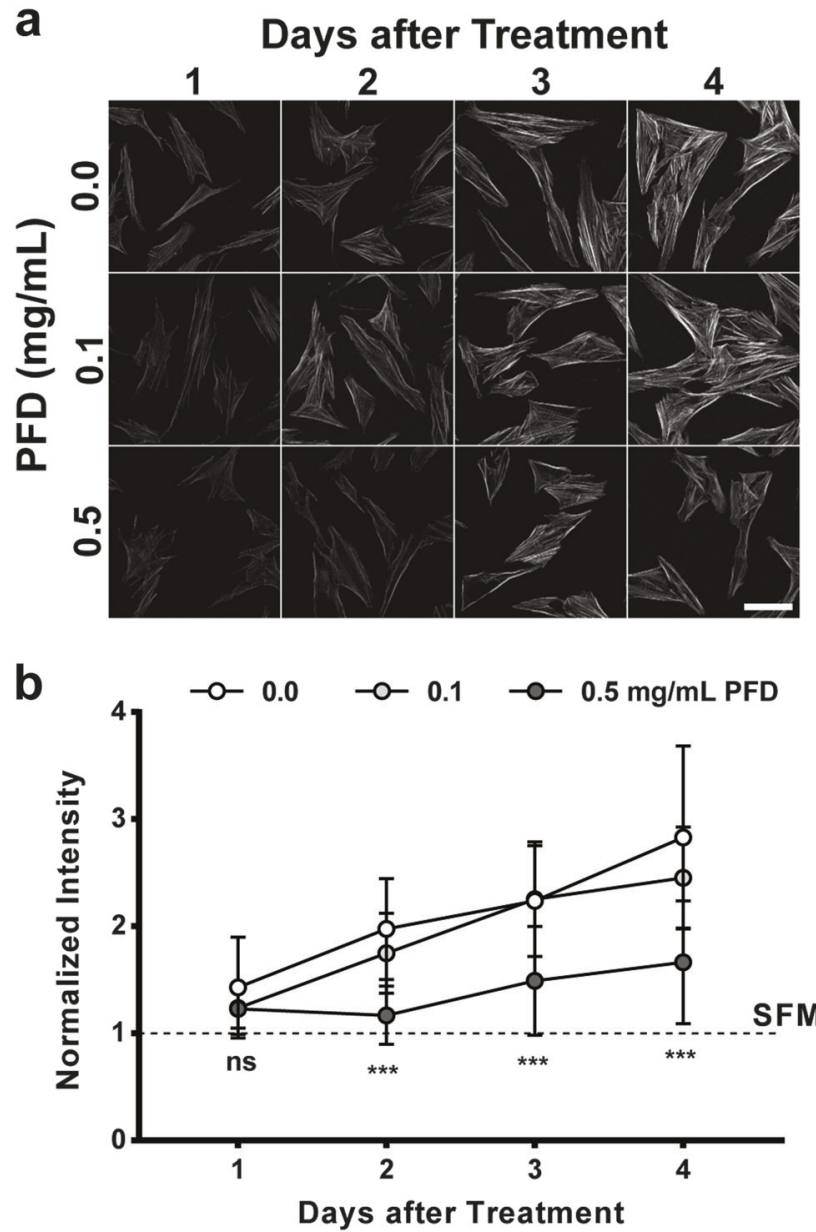

Fig. 4 PFD reduced F-actin stress fibers and size of focal adhesions in TGF- $\beta 1$-treated fibroblasts. Cells were treated with TGF- $\beta 1$ alone or in the presence of PFD and fixed 1-4 days later. a NHDF were stained for F-actin with Alexa Fluor 647 phalloidin. Scale bar is $100 \mu \mathrm{m}$. b Mean F-actin intensity per cell was measured for each image with ImageJ and compared to the mean intensity per image of untreated

fluorescently labeled phalloidin staining and quantification of mean fluorescent intensity per cell. Treatment with 0.5 $\mathrm{mg} / \mathrm{mL}$ PFD significantly decreased the F-actin signal after two to four days of TGF- $\beta 1$ treatment (Fig. $4 a, b$ ).

Large, super-mature focal adhesions that link contractile stress fibers to surrounding ECM were identified in TGF- $\beta 1$ treated NHDF by immunocytochemistry staining for vinculin (Fig. 4c). Treatment with $0.5 \mathrm{mg} / \mathrm{mL}$ PFD reduced the TGF- $\beta 1$ effect and such large complexes were not observed. To determine if PFD affected de novo focal adhesion formation, cells in complete media (FGM2) were pre-treated with or without $0.5 \mathrm{mg} / \mathrm{mL}$ PFD before plating onto chambered slides. No apparent differences in focal adhesion number or size were observed between treated and untreated cells at any of the measured times from $30 \mathrm{~min}$ to $6 \mathrm{~h}$ after plating (see images of cells fixed 30 min after seeding in Supplementary Figure S2).
C

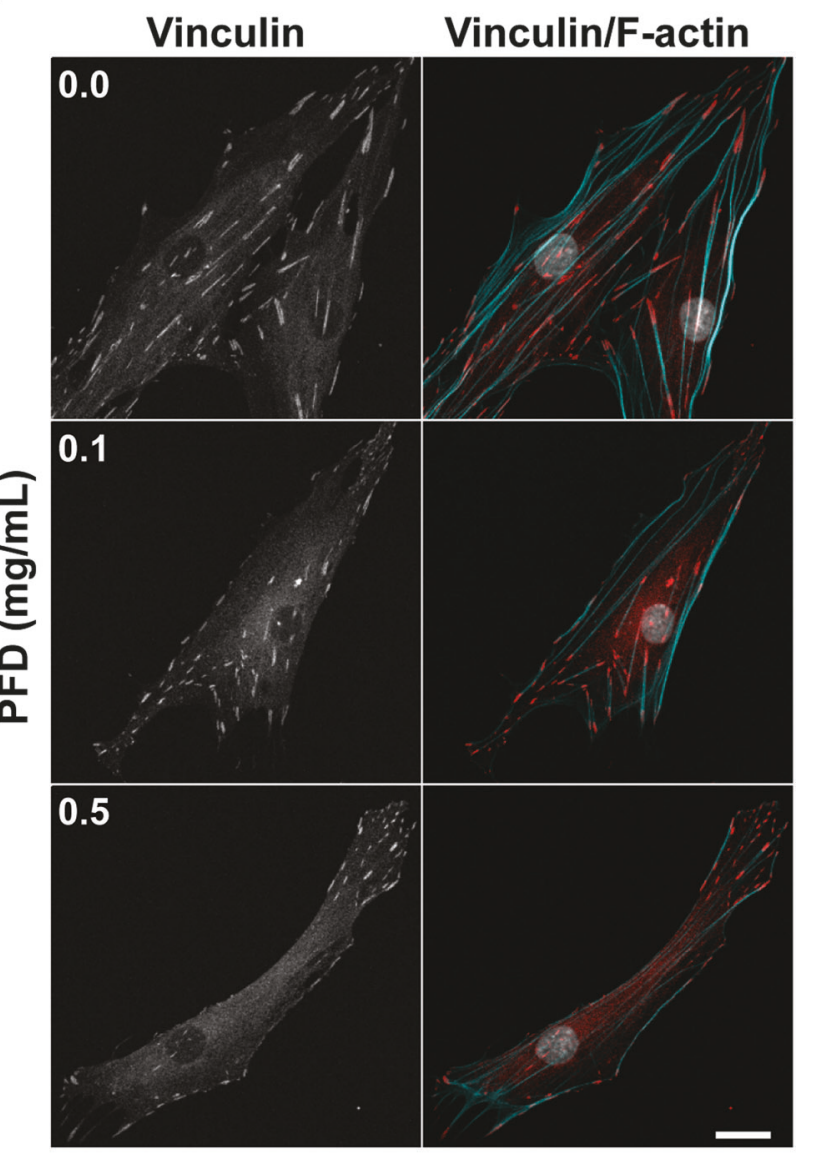

SFM at each time point. The average \pm s.d. over seven experimental runs is plotted for each treatment group over time. $* P<0.05, * * P<$ $0.01, * * * P<0.001$ compared with TGF- $\beta 1$ only (no PFD). c Cells fixed three days after treatment were stained for vinculin (red), F-actin (cyan), and Hoechst (white). Scale bar is $20 \mu \mathrm{m}$ (color figure online)

\section{PFD reduces migration rate of TGF- $\beta 1$-treated NHDF}

TGF- $\beta 1$ treatment produced a dose-dependent increase in maximum impedance recovery (Fig. 5a). This measure indicated the aggregate effect of TGF- $\beta 1$ on cell adhesion, spreading, and proliferation $[38,39]$. The stimulatory effect of $10 \mathrm{ng} / \mathrm{mL}$ TGF- $\beta 1$ was diminished in a dose-dependent manner by concurrent PFD treatment (Fig. 5b). Interestingly, the maximum impedance effects were also seen in unwounded samples (Supplementary Figure S3). In this data, an unperturbed confluent layer of cells was treated and showed both a dose-dependent increase in normalized impedance with TGF- $\beta 1$ treatment and inhibition by PFD.

We next assayed the effects of PFD on cell migration rate via ECIS 2D wounding assays. After wounding caused impedance to drop to baseline levels, the time for each well to recover halfway to its pre-wound confluent monolayer 


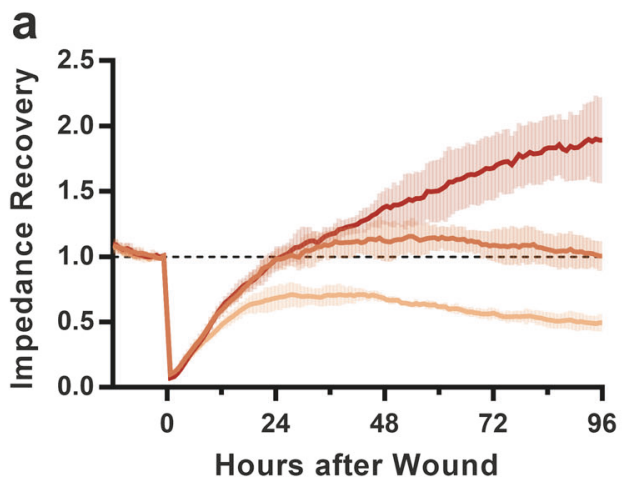

b
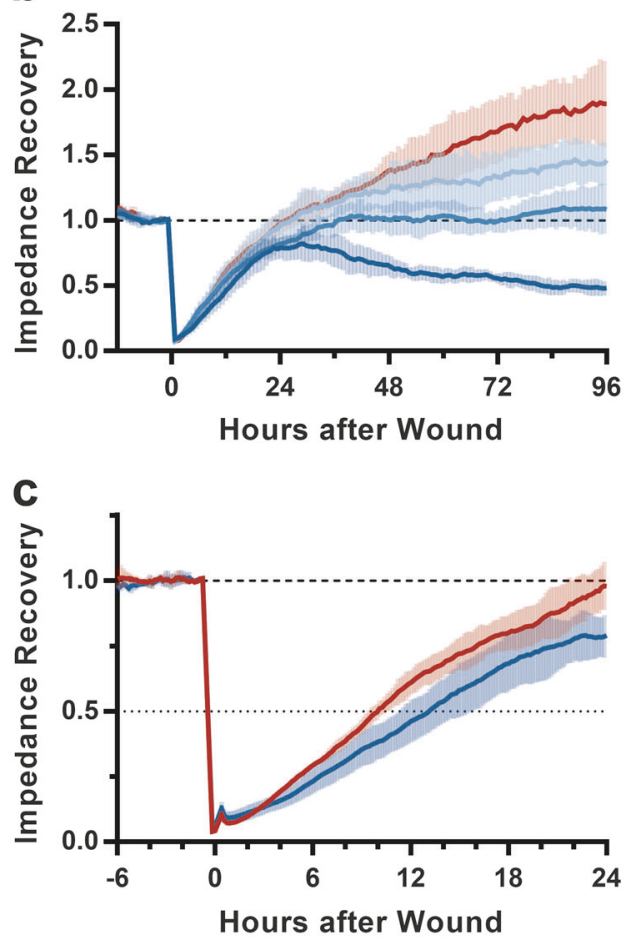

Fig. 5 PFD reduced proliferation, cell-substrate adhesion, and migration in TGF- $\beta 1$ treated fibroblasts. a Cells treated with 0,2 , or $10 \mathrm{ng} /$ $\mathrm{mL}$ TGF- $\beta 1$ after wounding recovered to maximum normalized impedance in a dose-related manner. b Simultaneous treatment with $10 \mathrm{ng} / \mathrm{mL}$ TGF- $\beta 1$ alone or in the presence of PFD $(0.1,0.5$, or $1.0 \mathrm{mg} /$ $\mathrm{mL}$ ) showed a dose-dependent drop in maximum impedance recovery. c Time to 0.5 normalized impedance recovery increased with the

impedance level was measured. This time increased significantly for the $1.0 \mathrm{mg} / \mathrm{mL}$ PFD treatment group indicating a reduced migration rate (note reduced slope of impedance trace in Fig. 5c).

\section{PFD targets p38-MAPK signaling}

Potential target(s) of PFD within TGF- $\beta 1$ signaling pathways were identified using a preliminary antibody array screen. TGF- $\beta 1$ activation of p38 MAP kinase was reduced
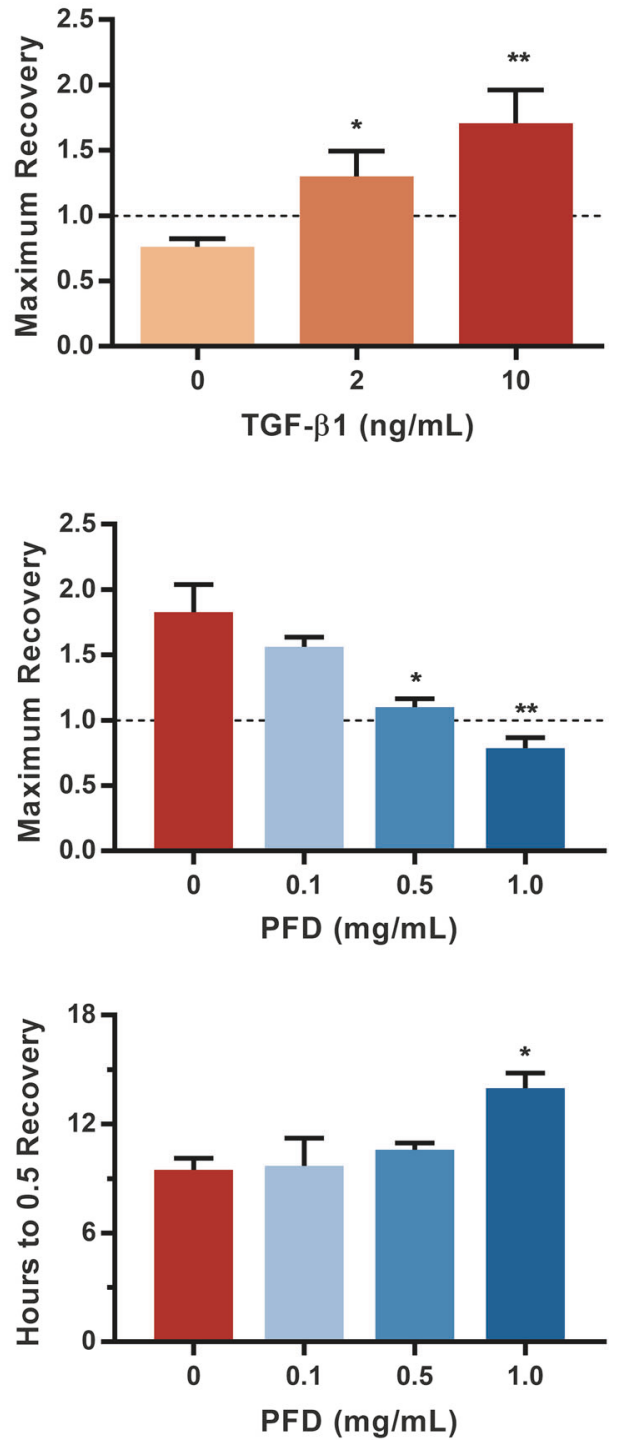

highest dose of PFD $(1.0 \mathrm{mg} / \mathrm{mL})$. Left panels show normalized impedance over time with average \pm s.d. for 4 replicate wells from one representative dataset of three. Right panels show average \pm s.d. of (a, b) maximum normalized impedance or (c) time to 0.5 normalized impedance recovery for the same 4 replicate wells. $* P<0.05$, $* * P<0.01$ compared with (a) SFM or (b, c) TGF- $\beta 1$ only (no PFD)

in lysates treated with $0.5 \mathrm{mg} / \mathrm{mL}$ PFD (data not shown). To validate these results, we measured the effects of PFD on activated levels of the canonical TGF- $\beta 1$ signaling mediator, SMAD2/3, and the non-canonical mediator, p38 MAPK (Fig. 6). The detectible level of phosphorylated-p38, normalized to total $\mathrm{p} 38$ protein, was significantly upregulated by TGF- $\beta 1$ as early as $5 \mathrm{~min}$ and continued to increase throughout the duration of the experiment ( 5 and $15 \mathrm{~min}$, Fig. 6a, 30 and $60 \mathrm{~min}$ data not shown). Treatment with PFD resulted in a dose-dependent reduction in 

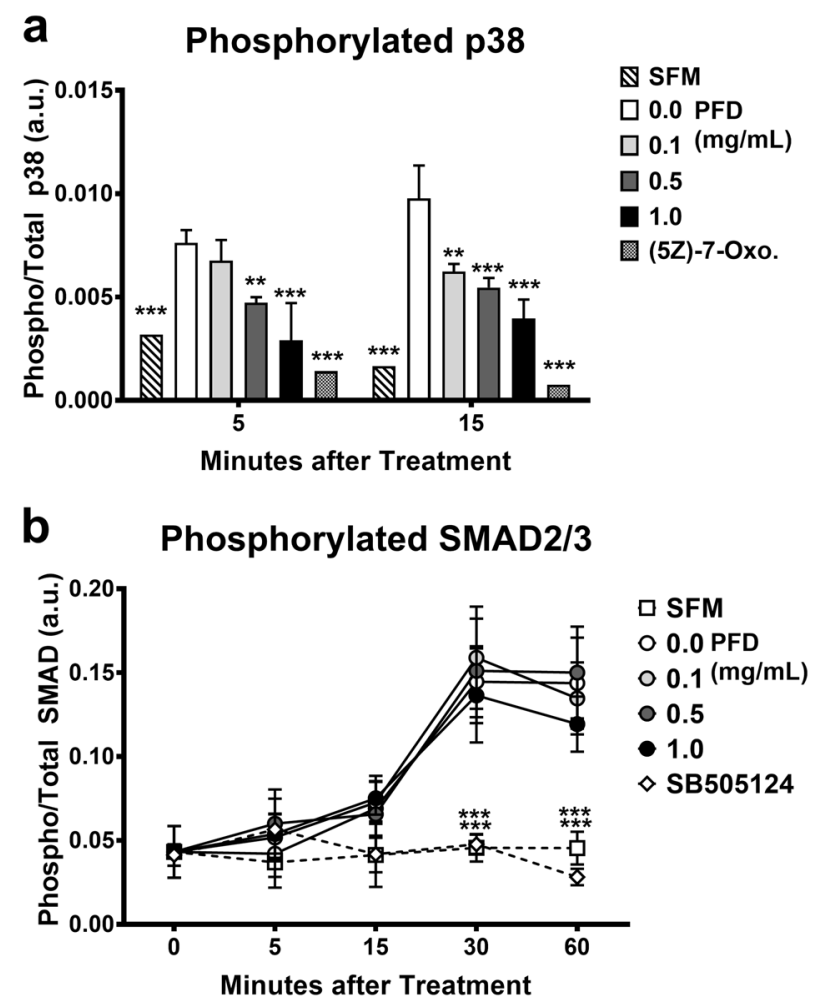

Fig. 6 PFD suppressed p38-mediated MAPK signaling. Phosphorylated and total protein levels of the kinase signaling mediators p38 and SMAD2/3 were detected by Western blot analysis in NHDF cells stimulated with TGF- $\beta 1$ alone or in the presence of PFD. Phospho-

phosphorylated p38 protein levels, similar to the reduction in phosphorylation seen in cells treated with the TAK $1 / \mathrm{p} 38$ inhibitor, 5(Z)-7-oxozeaneol (Fig. 6a). The lowest PFD dose, $0.1 \mathrm{mg} / \mathrm{mL}$, did not significantly reduce p38 activity until $15 \mathrm{~min}$, whereas 0.5 and $1.0 \mathrm{mg} / \mathrm{mL}$ PFD reduced $\mathrm{p} 38$ activity at a statistically significant level at both 5 and 15 min post-stimulation. PFD inhibition of phosphorylated-p38 was not observed at later time points (30 and $60 \mathrm{~min}$, data not shown). TGF- $\beta 1$ stimulation upregulated SMAD2/3 phosphorylation which was completely inhibited by treatment with the type I TGF- $\beta$ receptor inhibitor, SB505124, but not by PFD (Fig. 6b).

\section{PFD inhibits profibrotic gene expression}

Using a commercially available qRT-PCR primer array, we assayed the effect of PFD treatment on the TGF- $\beta 1$ stimulated RNA expression profile of 84 fibrosis-related genes over time $(0.5,1,2,3$ days after treatment). Of the 52 genes on the array with expression data that met the detection cut-off $(\mathrm{Ct}<30), 33$ were significantly regulated by TGF- $\beta 1$ stimulation as compared to SFM controls (Fig. 7a, Supplementary Table S1). TGF- $\beta 1$ stimulation caused an early and substantial induction of ACTA2 $(\alpha-$ protein levels are displayed relative to total protein levels for (a) p38 and (b) SMAD2/3. Data represents the average \pm s.d. of three replicate experiments. $* * P<0.01, * * * P<0.001$ compared with TGF- $\beta 1$ only (no PFD).

SMA) RNA expression that preceded the protein expression induction determined via immunocytochemistry and Western blot (Fig. 2). TGF- $\beta 1$-treated NHDF increased RNA expression of $A C T A 2$ after $12 \mathrm{~h}$ of treatment and continued to show increased expression up to 25 -fold higher than SFM control samples after three days (Fig. 7a, Supplementary Table S1). In addition, both collagen I and III showed small but statistically significant increases in RNA expression with TGF- $\beta 1$ treatment compared to SFM samples (see COLIA2 and COL3A1, Fig. 7a).

Treatment with $0.5 \mathrm{mg} / \mathrm{mL}$ PFD significantly altered the expression of 13 TGF- $\beta 1$-regulated genes (Fig. 7b, Supplementary Table S2). PFD reduced ACTA2 expression after three days of treatment (Fig. 7b, d, Supplementary Table S2). Of the remaining PFD-regulated genes, only connective tissue growth factor $(C T G F)$ demonstrated a significant response to the $0.1 \mathrm{mg} / \mathrm{mL}$ PFD (downregulated, data not shown). For matrix metalloproteinase 1 (MMP1), the TGF- $\beta 1$ inhibition was reversed by PFD treatment. The other PFD-regulated genes were upregulated by TGF- $\beta 1$ and treatment with PFD decreased this effect. The PFDregulated genes fell into four categories: TGF- $\beta$ signaling (TGFB2, TGFB3, and TGFBRI), focal adhesion components (ITGA3, ITGB1, ILK), ECM remodeling (MMP1, 
a

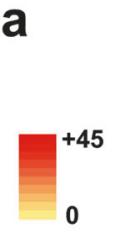

$+9.0$

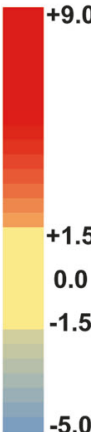

Fold

Regulation

(vs. SFM)
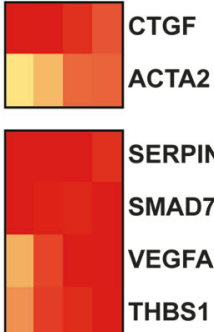

ERPINE1

SMAD7

VEGFA

THBS1

PDGFA

LTBP1

GREM1

TIMP3

ITGAV

ITGB1

ITGA1

ITGB5

ITGA3

COL1A2

COL3A1

LOX

TGIF1

TGFBR2

SERPINH1

TGFBR1

TGFB2

THBS2

JUN

DCN

PLAU

CAV1

IL13RA2

ITGA2

MMP1

MMP3

B2M

눙울우웅

Days after

Treatment b

Fold

Regulation

(vs. TGF)

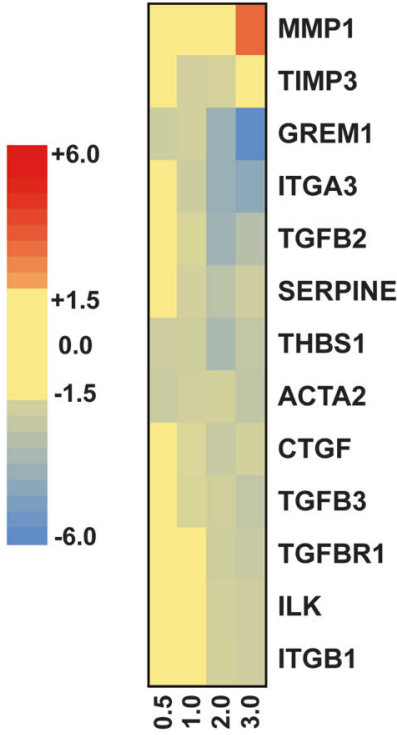

Days after

Treatment

\section{C}
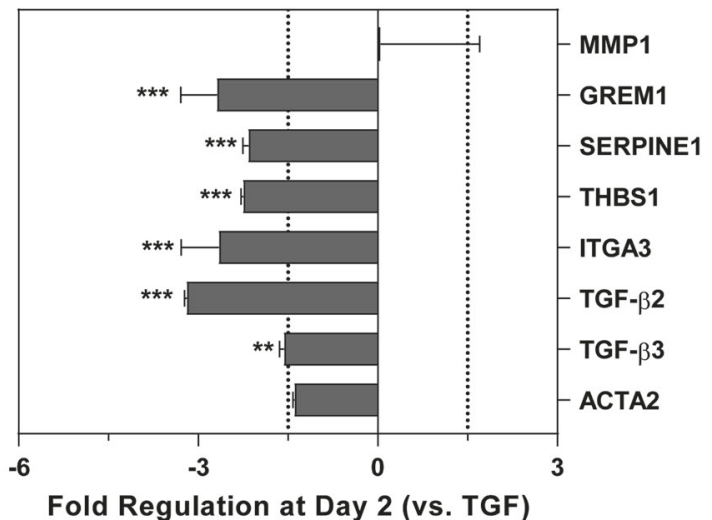

d

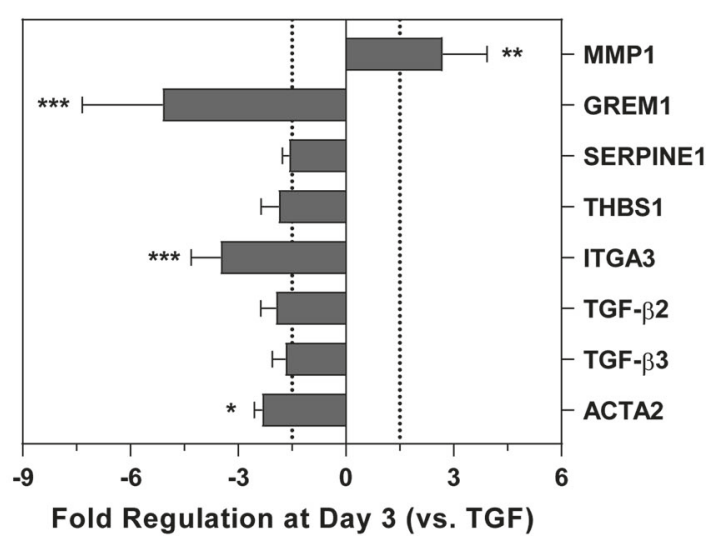

Fig. 7 PFD modulated expression of fibrosis-related genes. a Heatmap of fold-regulation over time for genes regulated by TGF- $\beta 1$ as compared to SFM control. Top scale bar applies only to CTGF and $A C T A 2$. Yellow shading denotes fold regulation values within \pm 1.5 cut-off. b Heatmap of fold regulation over time comparing treatment with TGF- $\beta 1$ and $0.5 \mathrm{mg} / \mathrm{mL}$ PFD to TGF- $\beta 1$ alone. Validation qRT-
PCR data is shown for eight differentially expressed genes after (c) 2 days treatment and (d) 3 days treatment. Data represents average $\pm \mathrm{s}$. d. of two independent experiments. $* P<0.05$, $* * P<0.01$, and $* * * P<0.001$ compared $\Delta \mathrm{C}_{\mathrm{T}}$ of TGF- $\beta 1+\mathrm{PFD}$ to TGF- $\beta 1$ alone (no PFD). Fold regulation calculated as $2^{-\Delta \Delta C T}$ and $-1 / 2^{-\Delta \Delta C T}$ for $2^{-\Delta \Delta C T}$ values $<1$ (color figure online) 
TIMP3), and other markers of fibrosis (GREM1, SERPINE1, THBS1, ACTA2, and CTGF). The strongest effects for $M M P 1, G R E M 1, I T G A 3$, and ACTA2 were seen after three days of treatment (Fig. 7b, d). Some of the other PFDmodulated genes showed a stronger response one day (TIMP3) or two days after treatment (TGFB2, THBS1, and $C T G F)$. Neither COL1A2 nor COL3A1 showed significant changes in expression with the PFD doses and times assayed $(0.1$ and $0.5 \mathrm{mg} / \mathrm{mL}$ PFD, 0.5-3 days after treatment, Supplementary Table S2). Validation qRT-PCR reactions were run for eight of the PFD-regulated genes as well as COLIA2 and COL3A1, all of which confirmed the array results (Fig. $7 \mathrm{c}, \mathrm{d} ; C O L 1 A 2$ and $C O L 3 A 1$ validation data not shown).

\section{Discussion}

In response to the need for an effective therapeutic for dermal fibrosis $[1,2,4,6]$, we assessed the in vitro antifibrotic effects of PFD on human dermal myofibroblasts. The findings of this study support PFD as a promising pharmacological agent that potently inhibits the development of fibrogenic dermal myofibroblast cells.

One feature of fibrosis is the continued proliferation of fibroblasts in the wound bed $[1,2,4]$. TGF- $\beta 1$ stimulates proliferation during both in vivo wound healing and in cultured monolayers of adult NHDF [8-12]. Previous studies demonstrated that PFD treatment arrests cells in G1 and inhibits cell proliferation in human Tenon's fibroblasts [40, 41] and murine mesenchymal stem cells [42]. Our results with dermal fibroblasts confirmed that PFD reduces TGF$\beta 1$-stimulated cell proliferation in a dose-dependent manner. We verified that the observed reduction in proliferation was not the result of PFD-induced apoptosis (Supplementary Figure S1). PFD treatment given at different times relative to TGF- $\beta 1$ remained effective and demonstrated the sustained potency of the drug. This supports preliminary clinical data for PFD used as either a prophylactic treatment to profibrotic injury (perioperative with surgery [24, 43]) or as a post-treatment (anti-scar therapeutic [26]). The observed PFD inhibition of cell proliferation may be mediated through its effects on CTGF. TGF- $\beta 1$-stimulated proliferation is CTGF-dependent [8] and we found that PFD reduced the TGF- $\beta 1$-stimulated upregulation of CTGF RNA expression.

TGF- $\beta 1$ drives normal fibroblast differentiation into profibrotic $\alpha-\mathrm{SMA}^{+}$myofibroblast cells [8-12]. PFD delayed and inhibited TGF- $\beta 1$-induced myofibroblast differentiation by reducing the expression of $\alpha$-SMA at both the RNA and protein levels. With $1.0 \mathrm{mg} / \mathrm{mL}$ PFD treatment, no $\alpha$-SMA protein was detectible. The $0.5 \mathrm{mg} / \mathrm{mL}$ PFD dose effectively delayed the fibroblast-to- myofibroblast transition. Immunocytochemistry experiments visually confirmed this finding as PFD treatment delayed initial $\alpha-\mathrm{SMA}^{+}$myofibroblast detection from day 2 to day 3.

Fully differentiated myofibroblasts are highly contractile cells that remodel surrounding ECM. This occurs through intracellular actomyosin contractions of F-actin stress fibers connected via focal adhesions to extracellular collagen and other matrix proteins [44]. PFD treatment inhibited each component in this mechanoregulatory system. PFD treatment reduced F-actin accumulation into stress fibers, prevented the development of large super-mature focal adhesions, and inhibited collagen protein production. Additionally, PFD treatment downregulated RNA expression of the focal adhesion components $\alpha_{3}$ and $\beta 1$ integrin. These integrin subunits are associated with myofibroblast differentiation and blocking either one of them can prevent myofibroblast differentiation [45].

Data from ECIS measurements confirmed that PFD treatment inhibited myofibroblast differentiation and reduced cell migration. In a dose-dependent manner, PFD reduced the maximum impedance achieved by TGF- $\beta 1$ stimulated cells. In this system, electrical impedance is an aggregate measure of cell morphology, substrate adhesion, and proliferation, thus our ECIS measurements confirm the results obtained from confocal imaging, focal adhesion immunocytochemistry, and WST-1 assays. PFD treatment also slowed the rate of cell migration. Due to the slow proliferation rate of NHDF ( $>24 \mathrm{~h}$ doubling time), it is unlikely that the impedance dynamics of migration (measured $<12 \mathrm{~h}$ after wounding) are confounded by the effects of any cell proliferation. Reduced cell migration can affect more than cell infiltration into a wound bed; it may also inhibit ECM contraction. Fibroblast migration through collagen ECM has been shown to contribute to matrix contraction and remodeling [44].

Differentiated myofibroblasts contribute to excessive ECM accumulation in dermal fibrosis by upregulating collagen production and reducing collagen turnover. TGF- $\beta 1$ decreases expression of matrix metalloproteinases and increases tissue inhibitor of metalloproteinases (TIMP). In our in vitro model, PFD inhibits the effect of TGF- $\beta 1$ by increasing $M M P 1$ gene expression and reducing that of TIMP3, which may allow for increased collagen turnover. PFD modulation of ECM production may occur in part through its inhibition of CTGF gene expression. CTGF has been shown to stimulate collagen production and can mediate TGF- $\beta 1$-induced ECM synthesis [46]. The qRTPCR array results also found significant changes to the fibrosis related gene GREM1. GREMLIN1 is a bone morphogenetic protein (BMP) 4 antagonist that is associated with fibrotic tissue, is upregulated by TGF- $\beta 1$, and reduces BMP4 inhibition of ECM production [47]. PFD inhibits the 
TGF- $\beta 1$ induced expression of GREM1, which may have the downstream effect of reducing ECM production.

Dermal fibrosis is associated with excessive collagen production and disorganized extracellular fibril bundle assembly [1-3]. In vitro studies of collagen biosynthesis are a useful first step when investigating antifibrotic agents, although culture conditions such as cell density and availability of ascorbic acid can alter both collagen production and the rate of its secretion [48-51]. Previous in vitro studies in various cell types and disease models demonstrated that PFD can affect collagen protein production [52], fibril assembly [53], or extracellular collagen production [54]. Our results in dermal fibroblasts support the inhibitory effects of PFD on collagen production reported in other test models. Here, PFD treatment resulted in a clear inhibition of TGF- $\beta 1$-induced collagen I and III production, although there were some differences in the kinetics and magnitude of detectible collagen between the different compartments measured. This could reflect differential effects of PFD on individual compartments along the collagen biosynthetic pathway and/or the contribution to collagen production and secretion of specific culture conditions used between detection techniques. Additionally, the lack of PFD effects on collagen types I and III in qRT-PCR experiments indicates that, in this system, PFD regulates collagen protein biosynthesis rather than transcription.

TGF- $\beta 1$ activation of its surface receptor complex results in activation of both canonical, SMAD-mediated, and noncanonical, SMAD-independent, signaling cascades. In the canonical TGF- $\beta 1$ signaling pathway, the SMAD2/3 protein complex is phosphorylated upon TGF- $\beta 1$ activation of its receptor complex and translocates to the nucleus where it interacts with other transcription factors to regulate transcriptional responses [55]. Our data clearly showed an upregulation of phosphorylated SMAD2/3 in response to TGF- $\beta 1$ stimulation, although PFD did not affect this response at any dose or time tested $(0.1,0.5$, or $1.0 \mathrm{mg} / \mathrm{mL}$ from 5 to $60 \mathrm{~min}$ after TGF- $\beta 1$ stimulation). This contrasts previous findings of PFD inhibition of SMAD phosphorylation in TGF- $\beta 1$-stimulated human lung fibroblasts and Dupuytren's disease-derived fibroblasts [27, 52]. This difference in PFD action may be due to differences in fibroblasts sourced from different tissues, disease states, and in vitro culture systems [56-58].

Non-canonical TGF- $\beta 1$ signaling occurs through a number of pathways including those of MAP kinase family members: p38, JNK, and ERK1/2. MAPK signaling coordinates numerous cell responses by activating substrate proteins involved in transcription, translation, and cell processes such as proliferation, migration, apoptosis, and structural cytoskeletal changes [59]. Previous studies of PFD effects on MAPK signaling report conflicting findings $[40,60-68]$. However, there is strong evidence for p38 as a primary effector of PFD function. Direct interaction of PFD with purified p38 kinase modulates p38 kinase activity [61] and PFD-treated pulmonary fibroblasts show reduced p38 activation $[52,62]$. We demonstrated PFD inhibition of $\mathrm{p} 38$ activity in a dermal system and observed a dose-dependent reduction in phosphorylated p38 within five minutes of TGF- $\beta 1$ stimulation. The inhibitory effects of PFD were potent but transient as the PFD effect to p38 activation was lost after $30 \mathrm{~min}$. Our data did not clarify whether PFD acted directly on p38 to inhibit its phosphorylation or on an upstream member of the relevant MAPK pathway, e.g., TAK1. Additional studies will help determine if PFD directly interacts with p38 or whether PFD activity targets upstream and/or adjacent signaling pathways.

In total, these results strongly support PFD as a promising antifibrotic agent for prophylaxis and treatment of dermal fibrosis. In normal human dermal fibroblasts, PFD inhibits fibrogenic signals of TGF- $\beta 1$ by abrogating p38-mediated MAPK activation, regulating transcription of profibrotic genes, and blocking myofibroblast differentiation. In accordance with previous studies conducted using non-dermal fibroblasts (Lin et al. [41]), PFD treatment of normal human dermal fibroblasts in the absence of TGF- $\beta 1$ also demonstrated significant inhibitory effects in proliferation and ECIS assays (data not shown). Future research into the mode of action by which PFD affects in vivo wound healing and fibroproliferative disorders of the skin is needed to fully validate the effectiveness of PFD as a topical antifibrotic agent.

Acknowledgements We would like to acknowledge Dr. James Aden for lending statistical analysis expertize and consultation. We also thank Dr. Exing Wang for assistance with image analysis techniques. This work was supported in part through the Congressionally Directed Medical Research Programs, U.S. Army Medical Research and Materiel Command W81XWH-15-2-0083 and the Naval Medical Research Center's Advanced Medical Development program (MIPR N3239815MHX040).

Author contributions Study design, data acquisition/analysis, and manuscript preparation was done in equal part by CLH and ARW. KPL originated the concept of the study and participated in the design of this study.

\section{Compliance with ethical standards}

Conflict of interest The authors declare that they have no conflict of interest.

\section{References}

1. Gauglitz GG, Korting HC, Pavicic T, et al. Hypertrophic scarring and keloids: pathomechanisms and current and emerging treatment strategies. Mol Med. 2011;17:113-25.

2. Wynn TA. Common and unique mechanisms regulate fibrosis in various fibroproliferative diseases. J Clin Invest. 2007;117: $524-9$. 
3. Butzelaar L, Ulrich MM, Mink van der Molen AB, et al. Currently known risk factors for hypertrophic skin scarring: a review. J Plast Reconstr Aesthet Surg. 2016;69:163-9.

4. Chiang RS, Borovikova AA, King K, et al. Current concepts related to hypertrophic scarring in burn injuries. Wound Repair Regen. 2016;24:466-77.

5. Reinke JM, Sorg H. Wound repair and regeneration. Eur Surg Res. 2012;49:35-43.

6. Rowan MP, Cancio LC, Elster EA, et al. Burn wound healing and treatment: review and advancements. Crit Care. 2015;19:243.

7. Tredget EE, Levi B, Donelan MB. Biology and principles of scar management and burn reconstruction. Surg Clin N Am. 2014;94:793-815.

8. Grotendorst GR, Rahmanie H, Duncan MR. Combinatorial signaling pathways determine fibroblast proliferation and myofibroblast differentiation. FASEB J. 2004;18:469-79.

9. Pratsinis H, Giannouli CC, Zervolea I, et al. Differential proliferative response of fetal and adult human skin fibroblasts to transforming growth factor-beta. Wound Repair Regen. 2004;12:374-83.

10. Bettinger DA, Yager DR, Diegelmann RF, et al. The effect of TGF-beta on keloid fibroblast proliferation and collagen synthesis. Plast Reconstr Surg. 1996;98:827-33.

11. Strutz F, Zeisberg M, Renziehausen A, et al. TGF-beta 1 induces proliferation in human renal fibroblasts via induction of basic fibroblast growth factor (FGF-2). Kidney Int. 2001;59:579-92.

12. Hinz B. Formation and function of the myofibroblast during tissue repair. J Invest Dermatol. 2007;127:526-37.

13. Hinz B, Celetta G, Tomasek JJ, et al. Alpha-smooth muscle actin expression upregulates fibroblast contractile activity. Mol Biol Cell. 2001;12:2730-41.

14. Kassianidou E, Kumar S. A biomechanical perspective on stress fiber structure and function. Biochim Biophys Acta. 2015;1853:3065-74.

15. Dugina V, Fontao L, Chaponnier C, et al. Focal adhesion features during myofibroblastic differentiation are controlled by intracellular and extracellular factors. J Cell Sci. 2001;114:3285-96.

16. Riekki R, Parikka M, Jukkola A, et al. Increased expression of collagen types I and III in human skin as a consequence of radiotherapy. Arch Dermatol Res. 2002;294:178-84.

17. Oliveira GV, Hawkins HK, Chinkes D, et al. Hypertrophic versus non hypertrophic scars compared by immunohistochemistry and laser confocal microscopy: type I and III collagens. Int Wound J. 2009;6:445-52.

18. Cheng WRY, Ning F, Zhang G. The content and ratio of type I and III collagen in skin differ with age and injury. Afr J Biotechnol. 2011;10:2524-9.

19. Syed F, Ahmadi E, Iqbal SA, et al. Fibroblasts from the growing margin of keloid scars produce higher levels of collagen I and III compared with intralesional and extralesional sites: clinical implications for lesional site-directed therapy. $\mathrm{Br} \mathrm{J}$ Dermatol. 2011;164:83-96.

20. White B, Osier C, Gletsu N, et al. Abnormal primary tissue collagen composition in the skin of recurrent incisional hernia patients. Am Surg. 2007;73:1254-8.

21. Penn JW, Grobbelaar AO, Rolfe KJ. The role of the TGF-beta family in wound healing, burns and scarring: a review. Int J Burns Trauma. 2012;2:18-28.

22. Macias-Barragan J, Sandoval-Rodriguez A, Navarro-Partida J, et al. The multifaceted role of pirfenidone and its novel targets. Fibrogenes Tissue Repair. 2010;3:16.

23. Richeldi L, Yasothan U, Kirkpatrick P. Pirfenidone. Nat Rev Drug Discov. 2011;10:489-90.

24. Cantu-Cantu MZ, Lyra-Gonzalez I, Armendariz-Borunda J. Coadjuvant treatment with surgery and pirfenidone in severe facial trauma due to dog bite. J Craniofac Surg. 2013;24:675-8.
25. Janka-Zires $M$, Almeda-Valdes $P$, Uribe-Wiechers AC, et al. Topical administration of pirfenidone increases healing of chronic diabetic foot ulcers: a randomized crossover study. J Diabetes Res. 2016;2016:7340641.

26. Armendariz-Borunda J, Lyra-Gonzalez I, Medina-Preciado D, et al. A controlled clinical trial with pirfenidone in the treatment of pathological skin scarring caused by burns in pediatric patients. Ann Plast Surg. 2012;68:22-28.

27. Zhou C, Liu F, Gallo PH, et al. Anti-fibrotic action of pirfenidone in Dupuytren's disease-derived fibroblasts. BMC Musculoskelet Disord. 2016;17:469.

28. Saito M, Yamazaki M, Maeda T, et al. Pirfenidone suppresses keloid fibroblast-embedded collagen gel contraction. Arch Dermatol Res. 2012;304:217-22.

29. Carpenter AE, Jones TR, Lamprecht MR, et al. CellProfiler: image analysis software for identifying and quantifying cell phenotypes. Genome Biol. 2006;7:R100.

30. Rondanino C, Rojas R, Ruiz WG, et al. RhoB-dependent modulation of postendocytic traffic in polarized Madin-Darby canine kidney cells. Traffic. 2007;8:932-49.

31. Harris VM. Protein detection by simple western analysis. Methods Mol Biol. 2015;1312:465-8.

32. Liu S-B, Sardi S, Sonom B, et al. The application of a novel nanovolume capillary electrophoresis-based protein analysis system in personalized \& translational medicine research. J Bioanal Biomed. 2013;S3.

33. Hamm M, Ha S, Rustandi RR. Automated capillary Western dot blot method for the identity of a 15-valent pneumococcal conjugate vaccine. Anal Biochem. 2015;478:33-39.

34. Ali AH, Mundi M, Koutsari C, et al. Adipose tissue free fatty acid storage in vivo: effects of insulin versus niacin as a control for suppression of lipolysis. Diabetes. 2015;64:2828-35.

35. Livak KJ, Schmittgen TD. Analysis of relative gene expression data using real-time quantitative PCR and the 2(-Delta Delta C(T)) method. Methods. 2001;25:402-8.

36. Sandbo N, Lau A, Kach J, et al. Delayed stress fiber formation mediates pulmonary myofibroblast differentiation in response to TGF-beta. Am J Physiol Lung Cell Mol Physiol. 2011;301: L656-666.

37. Sandbo N, Dulin N. Actin cytoskeleton in myofibroblast differentiation: ultrastructure defining form and driving function. Transl Res. 2011;158:181-96.

38. Reddy L, Wang HS, Keese CR, et al. Assessment of rapid morphological changes associated with elevated cAMP levels in human orbital fibroblasts. Exp Cell Res. 1998;245:360-7.

39. Wegener J, Keese CR, Giaever I. Electric cell-substrate impedance sensing (ECIS) as a noninvasive means to monitor the kinetics of cell spreading to artificial surfaces. Exp Cell Res. 2000;259:158-66.

40. Guo X, Yang Y, Liu L, et al. Pirfenidone induces G1 arrest in human tenon's fibroblasts in vitro involving AKT and MAPK signaling pathways. J Ocul Pharmacol Ther. 2017;33:366-74.

41. Lin $\mathrm{X}, \mathrm{Yu} \mathrm{M}, \mathrm{Wu} \mathrm{K}$, et al. Effects of pirfenidone on proliferation, migration, and collagen contraction of human Tenon's fibroblasts in vitro. Invest Ophthalmol Vis Sci. 2009;50:3763-70.

42. Jin SF, Ma HL, Liu ZL, et al. XL413, a cell division cycle 7 kinase inhibitor enhanced the anti-fibrotic effect of pirfenidone on TGF-beta1-stimulated C3H10T1/2 cells via Smad2/4. Exp Cell Res. 2015;339:289-99.

43. Iwata $\mathrm{T}$, Yoshida $\mathrm{S}$, Nagato $\mathrm{K}$, et al. Experience with perioperative pirfenidone for lung cancer surgery in patients with idiopathic pulmonary fibrosis. Surg Today. 2015;45: 1263-70.

44. Tomasek JJ, Gabbiani G, Hinz B, et al. Myofibroblasts and mechano-regulation of connective tissue remodelling. Nat Rev Mol Cell Biol. 2002;3:349-63. 
45. Darby IA, Laverdet B, Bonte F, et al. Fibroblasts and myofibroblasts in wound healing. Clin Cosmet Investig Dermatol. 2014;7:301-11.

46. Hu X, Wang H, Liu J, et al. The role of ERK and JNK signaling in connective tissue growth factor induced extracellular matrix protein production and scar formation. Arch Dermatol Res. 2013;305:433-45.

47. O'Reilly S, Ciechomska M, Cant R, et al. Interleukin-6 (IL-6) trans signaling drives a STAT3-dependent pathway that leads to hyperactive transforming growth factor-beta (TGF-beta) signaling promoting SMAD3 activation and fibrosis via Gremlin protein. J Biol Chem. 2014;289:9952-60.

48. Aumailley M, Krieg T, Razaka G, et al. Influence of cell density on collagen biosynthesis in fibroblast cultures. Biochem $\mathrm{J}$. 1982;206:505-10.

49. Schwarz RI, Mandell RB, Bissell MJ. Ascorbate induction of collagen synthesis as a means for elucidating a mechanism of quantitative control of tissue-specific function. Mol Cell Biol. 1981;1:843-53.

50. Schwarz RI. Collagen I and the fibroblast: high protein expression requires a new paradigm of post-transcriptional, feedback regulation. Biochem Biophys Rep. 2015;3:38-44.

51. Chen CZ, Raghunath M. Focus on collagen: in vitro systems to study fibrogenesis and antifibrosis state of the art. Fibrogenes Tissue Repair. 2009;2:7.

52. Conte E, Gili E, Fagone E, et al. Effect of pirfenidone on proliferation, TGF-beta-induced myofibroblast differentiation and fibrogenic activity of primary human lung fibroblasts. Eur J Pharm Sci. 2014;58:13-19.

53. Knuppel L, Ishikawa $\mathrm{Y}$, Aichler M, et al. A novel antifibrotic mechanism of nintedanib and pirfenidone. Inhibition of collagen fibril assembly. Am J Respir Cell Mol Biol. 2017;57: 77-90.

54. Zanotti S, Bragato C, Zucchella A, et al. Anti-fibrotic effect of pirfenidone in muscle derived-fibroblasts from Duchenne muscular dystrophy patients. Life Sci. 2016;145:127-36.

55. Akhurst RJ, Hata A. Targeting the TGFbeta signalling pathway in disease. Nat Rev Drug Discov. 2012;11:790-811.

56. Chang HY, Chi JT, Dudoit S, et al. Diversity, topographic differentiation, and positional memory in human fibroblasts. Proc Natl Acad Sci USA. 2002;99:12877-82.
57. Thannickal VJ, Lee DY, White ES, et al. Myofibroblast differentiation by transforming growth factor-beta1 is dependent on cell adhesion and integrin signaling via focal adhesion kinase. J Biol Chem. 2003;278:12384-9.

58. Chipev CC, Simon M. Phenotypic differences between dermal fibroblasts from different body sites determine their responses to tension and TGFbeta1. BMC Dermatol. 2002;2:13.

59. Burkhard K, Shapiro P. Use of inhibitors in the study of MAP kinases. Methods Mol Biol. 2010;661:107-22.

60. Peng Y, Yang H, Zhu T, et al. The antihepatic fibrotic effects of fluorofenidone via MAPK signalling pathways. Eur J Clin Invest. 2013;43:358-68.

61. Ma Z, Pan Y, Huang W, et al. Synthesis and biological evaluation of the pirfenidone derivatives as antifibrotic agents. Bioorg Med Chem Lett. 2014;24:220-3.

62. Haak AJ, Girtman MA, Ali MF, et al. Phenylpyrrolidine structural mimics of pirfenidone lacking antifibrotic activity: a new tool for mechanism of action studies. Eur $\mathrm{J}$ Pharmacol. 2017;811:87-92.

63. Navarro-Partida J, Martinez-Rizo AB, Gonzalez-Cuevas J, et al. Pirfenidone restricts Th2 differentiation in vitro and limits Th2 response in experimental liver fibrosis. Eur J Pharmacol. 2012;678:71-77.

64. Lee KW, Everett TH, Rahmutula D, et al. Pirfenidone prevents the development of a vulnerable substrate for atrial fibrillation in a canine model of heart failure. Circulation. 2006;114: 1703-12.

65. Choi K, Lee K, Ryu SW, et al. Pirfenidone inhibits transforming growth factor-beta1-induced fibrogenesis by blocking nuclear translocation of Smads in human retinal pigment epithelial cell line ARPE-19. Mol Vis. 2012;18:1010-20.

66. Li C, Han R, Kang L, et al. Pirfenidone controls the feedback loop of the AT1R/p38 MAPK/renin-angiotensin system axis by regulating liver $\mathrm{X}$ receptor-alpha in myocardial infarction-induced cardiac fibrosis. Sci Rep. 2017;7:40523.

67. Bizargity P, Liu K, Wang L, et al. Inhibitory effects of pirfenidone on dendritic cells and lung allograft rejection. Transplantation. 2012;94:114-22.

68. Nakazato H, Oku H, Yamane S, et al. A novel anti-fibrotic agent pirfenidone suppresses tumor necrosis factor-alpha at the translational level. Eur J Pharmacol. 2002;446:177-85. 